\title{
Interferon activity is not detected in blastocyst secretions and does not induce decidualization in mice
}

\author{
D. J. Baker and G. L. Nieder \\ Department of Anatomy, Wright State University School of Medicine Dayton, Ohio 45435, USA
}

\begin{abstract}
Summary. Mouse trophoblast cells synthesized and secreted proteins during the periimplantation period, some in the molecular size range of alpha interferons (IFN- $\alpha$ ), known mediators of the maternal recognition of pregnancy in sheep and cows. However, conditioned media samples containing secreted proteins from Day-5 mouse blastocysts or from trophoblast outgrowths did not contain detectable levels of antiviral activity indicative of IFN. In addition, it was not possible to induce a decidual reaction in suitably sensitized uteri with intraluminal instillation of IFN- $\alpha$. The results indicate that IFNs are probably not involved in the maternal recognition of pregnancy at the time of implantation in the mouse.
\end{abstract}

Key'u'ords: blastocyst; interferon; implantation; decidual reaction; mouse

\section{Introduction}

The establishment and maintenance of pregnancy is dependent on communication between the developing embryo and the maternal system. In sheep and cows the chemical signals that trigger maternal recognition of pregnancy are proteins secreted by the trophoblast of the peri-implantation embryo (see review by Roberts, 1989). Ovine trophoblast protein-1 (oTP-1) and bovine trophoblast protein-1 (bTP-1) have, via a uterine mechanism, antiluteolytic properties. Demonstrated effects of these proteins on the uterus include inhibition of prostaglandin F- $2 \alpha$ release and changes in endometrial protein secretion. Both proteins exhibit a high sequence homology with alpha interferons (IFN- $\alpha$ ) and have antiviral activity. Whether the secretion of interferon-like proteins is a general mechanism for the recognition of pregnancy in many species, or is only a characteristic of ungulates, is not yet known.

The existence of a peri-implantation, embryonic protein-mediated recognition of pregnancy in rodents has not been demonstrated. However, in the mouse, the trophoblast cells of the blastocyst do secrete proteins during the peri-implantation period (Nieder et al., 1987; Nieder, 1989; Nieder \& Baker, 1989). Significant changes in blastocyst secretion are coincident with the increase in uterine vascular permeability (pontamine blue reaction) and modification of endometrial protein secretion during the initiation of decidualization (Nieder et al., 1987; Nieder \& Macon, 1987; Weitlauf \& Suda-Hartman, 1988). Trophoblast secretion presumably continues to change during invasion of the endometrium since trophoblast outgrowth in vitro is accompanied by marked changes in protein secretion patterns (Nieder \& Baker, 1989). Several of these secreted proteins have molecular weights in the range of mouse IFN- $\alpha, 20000-22000$ (Schellekens \& van der Meide, 1987).

If interferon-like proteins are involved in the recognition of pregnancy during implantation in the mouse, secreted trophoblast proteins should have demonstrable antiviral activity. Also, purified mouse IFN- $\alpha$ should induce decidualization when instilled into a suitably sensitized uterus. The present study tested this hypothesis by assessing antiviral activity in embryo-conditioned medium from Day- 5 blastocysts and from blastocysts growing out in vitro. In addition, the ability of mouse IFN- $\alpha$ to induce decidualization was determined. 


\section{Materials and Methods}

Collection of embryos. Virgin white Swiss mice (6-8 weeks of age) were induced to ovulate with gonadotrophins (Fowler \& Edwards, 1957) and mated with fertile males. The presence of a vaginal plug confirmed mating and was designated as Day 1 of pregnancy. Females were kilied between 09:00 and 11:00 on the morning of Day 5 and embryos were flushed from the uterus with Dulbecco's phosphate-buffered saline (DPBS; Gibco, Grand Island, NY, USA) containing $0.1 \mathrm{mg}$ Fraction V bovine serum albumin/ml (BSA: Sigma, St Louis, MO, USA; lot No. 45F-0065).

Production of embryo-conditioned medium for anti-viral activity assay. In Exp. 1, 52 Day-5 embryos were cultured for $24 \mathrm{~h}$ in a single well of a 96-well plate (Corning Glass Works, Corning, NY, USA) in $50 \mu 1$ Dulbecco's modified Eagle's medum (DMEM; Gibco, Grand lsland, NY, USA) containing $4 \mathrm{mg} \mathrm{BSA} / \mathrm{ml}$ at $37^{\circ} \mathrm{C}$ in a $5 \% \mathrm{CO}_{2}$ atmosphere. Embryo-conditioned medium was centrifuged to remove any cells or debris. The blastocysts were placed into fresh DMEM and lysed by 3 freeze-thaw cycles. In Exp. 2, 47 Day-5 blastocysts were cultured in a fibronectin-coated well of a 96-well plate to facilitate attachment and outgrowth of the trophoblast (Armant et al., 1986). The well was coated by adding $100 \mu \mathrm{l}$ DPBS containing $100 \mu \mathrm{g}$ bovine plasma fibronectin/ml (Calbiochem, La Jolla, CA, USA) and incubating at $37^{\circ} \mathrm{C}$ for $4 \mathrm{~h}$. The wells were rinsed with three changes of DPBS and $50 \mu$ DMEM with $4.0 \mathrm{mg} \mathrm{BSA} / \mathrm{ml}$ were added. After $24 \mathrm{~h}$, embryo-conditioned medium was aspirated from the cultures and fresh DMEM was added. After an additional $24 \mathrm{~h}$, this second embryo-conditioned medium was collected and the attached embryos were lysed in fresh DMEM. Control medium was incubated for $24 \mathrm{~h}$ without embryos.

Antiviral activity assay. Antiviral activity in control and conditioned media and embryo lysates was determined using a cytopathic effect assay (Campbell et al., 1975). Mouse L929 cells, $4.5 \times 10^{4}$ cells/well of a 96-well plate, were cultured in Minimum Essential Medium (MEM, Gibco, Grand Island, NY, USA) containing 10\% fetal calf serum (FCS) at $37^{\circ} \mathrm{C}$ under a $2 \% \mathrm{CO}_{2}$ atmosphere. When cells reached confluence, the medium was replaced with $100 \mu \mathrm{l}$ MEM containing $2 \%$ FCS to which various amounts of embryo conditioned medium, embryo lysates, control medium or mouse IFN- $\alpha$ or IFN- $\beta$ standards (Lee Biomolecular, San Diego, CA, USA) were added. To produce serially diluted samples, $50 \mu \mathrm{l}$ embryo-conditioned medium were added to one well, then 7 successive $1: 3$ dilutions were made for additional wells. Similar dilutions were made for control medium and embryo lysates. Standard IFN- $\alpha$, 110 units, and IFN- $\beta, 380$ units, were added to other wells and also serially diluted 1:3 yielding IFN concentrations over the expected sensitivity range of the assay. After incubation for $18-20 \mathrm{~h}$, the cells were challenged with vesicular stomatitis virus. Media were replaced with $25 \mu$ virus (at a concentration to yield $30-50$ plaques/well) and incubated at $37^{\circ} \mathrm{C}$ for $45-60 \mathrm{~min}$. At the end of the incubation period the virus was discarded and the wells overlayed with $50 \mu \mathrm{l}$ $1 \%$ methylcellulose. The plates were incubated for $24-48 \mathrm{~h}$ or until plaques were defined. The methyl cellulose was discarded and the plates stained with $1 \%$ crystal violet for $5 \mathrm{~min}$ followed by several washes in cold water. The number of plaques in each well was determined. Antiviral activity in the samples was defined by a reduction of plaques, with 1 unit being the amount of activity reducing plaque formation $50 \%$ in this assay.

Production of labelled embryo-conditioned medium for electrophoresis. Day-5 embryos (20-30) were either placed immediately in labelling medium (see below) or placed in fibronectin-coated plates and grown-out for $24 \mathrm{~h}$ as described above before labelling. After collection, or following the culture period, $50 \mu \mathrm{l}$ of labelling medium, BMOC-3 (Brinster, 1971) containing 0.1 mg BSA $/ \mathrm{ml}$ and $200 \mu \mathrm{Ci}\left[{ }^{35} S\right]$ methionine $/ \mathrm{ml}$ (sp. act. $\sim 1100 \mathrm{Ci} / \mathrm{mmol}$; New England Nuclear, Boston, MA, USA), were added to the embryos. Following a 3 -h incubation at $37^{\circ} \mathrm{C}$ under a $5 \% \mathrm{CO}_{2}$ atmosphere, the conditioned medium containing labelled secreted proteins was centrifuged to remove any debris and lyophilized. The lyophilized medium was reconstituted in $35 \mu \mathrm{l}$ of electrophoresis lysis buffer containing $8 \mathrm{M}$-urea, $4 \%$ Nonidet P-40 and 2\% pH 3.5-9.5 ampholytes (Ampholine, LKB, Gaithersburg, MD, USA), and stored at - 70 C until assayed.

Two-dimensional electrophoresis. Proteins in the conditioned media samples were separated by two-dimensional electrophoresis under conditions described previously (Nieder et al., 1987). TCA-precipitable ${ }^{35} \mathrm{~S}$ was measured in $3 \mu \mathrm{l}$ samples before electrophoresis and about 10000 d.p.m. of labelled protein were loaded onto each gel. The first dimension was an isoelectric focussing separation in a $3 \cdot 5-9 \cdot 5 \mathrm{pH}$ gradient run for $12000-15000$ volt $\cdot$ hours. The second dimension was a $10-18 \%$ linear gradient polyacrylamide-SDS slab gel, run at a constant $4 \mathrm{~W}$ per slab. After fixation in $30 \%$ methanol $+7 \%$ acetic acid, the gels were saturated with fluorographic reagent (Amplify, Amersham, Arlington Heights, IL, USA) and dried onto filter paper. Gels were exposed on Kodak XAR-5 X-ray film at $-70^{\circ} \mathrm{C}$ for 7 days.

Induction of decidualization. Virgin white Swiss mice, 6-10 weeks of age, were ovariectomized under pentobarbitone anaesthesia $(50 \mathrm{mg} / \mathrm{kg})$. At 5 days after surgery, a priming regimen described by Finn \& Martin (1972) was begun. Briefly, $0 \cdot 1 \mu \mathrm{g}$ oestradiol- $17 \beta$ was administered on Days $1-3$, no injections were given on Days $4-6$ followed by $1 \mathrm{mg}$ progesterone on Days 7 and 8 . On Day $9,1 \mathrm{mg}$ progesterone plus $6.7 \mathrm{ng}$ oestradiol-17 $\beta$ were administered to obtain sensitized uteri. All hormones were injected subcutaneously in sesame oil between 08:00 and 10:00 h. At $7 \mathrm{~h}$ after the Day 9 injection, animals were again anaesthesized. Then $10 \mu \mathrm{l}$ of mouse IFN- $\alpha$ at various concentrations, or DPBS vehicle, were instilled into the randomly chosen right or left uterine horn, just distal to the uterotubal junction and $10 \mu \mathrm{l}$ peanut oil were instilled into the remaining horn to give a positive control for uterine sensitization in each animal. The animals given $1 \mathrm{mg}$ progesterone plus $6.7 \mathrm{ng}$ oestradiol-17 $\mathrm{\beta}$ on Days 10 and 11 were killed on Day 12 ; the uterine horns were removed and weighed. 


\section{Results}

\section{Protein secretion by peri-attachment blastocysts}

Consistent with previous experiments, Day-5 blastocysts synthesized and secreted more than 20 electrophoretically separable proteins (Fig. 1). Some of these proteins are within the molecular weight range of mouse IFN- $\alpha$. When Day-5 embryos were cultured on fibronectin-coated plates in serum-free medium, attachment and outgrowth was observed within $24 \mathrm{~h}$. Trophoblast outgrowth was accompanied by marked changes in protein secretion (Fig. 2), most notably the production of an acidic protein of $M_{r} 30000-40000$ with multiple isoelectric forms. Other 'new' proteins were also produced which were not found in Day-5 blastocyst-conditioned medium. Some of the proteins which were secreted by Day-5 blastocysts were still present during outgrowth, but made up a small proportion of the total secretions.

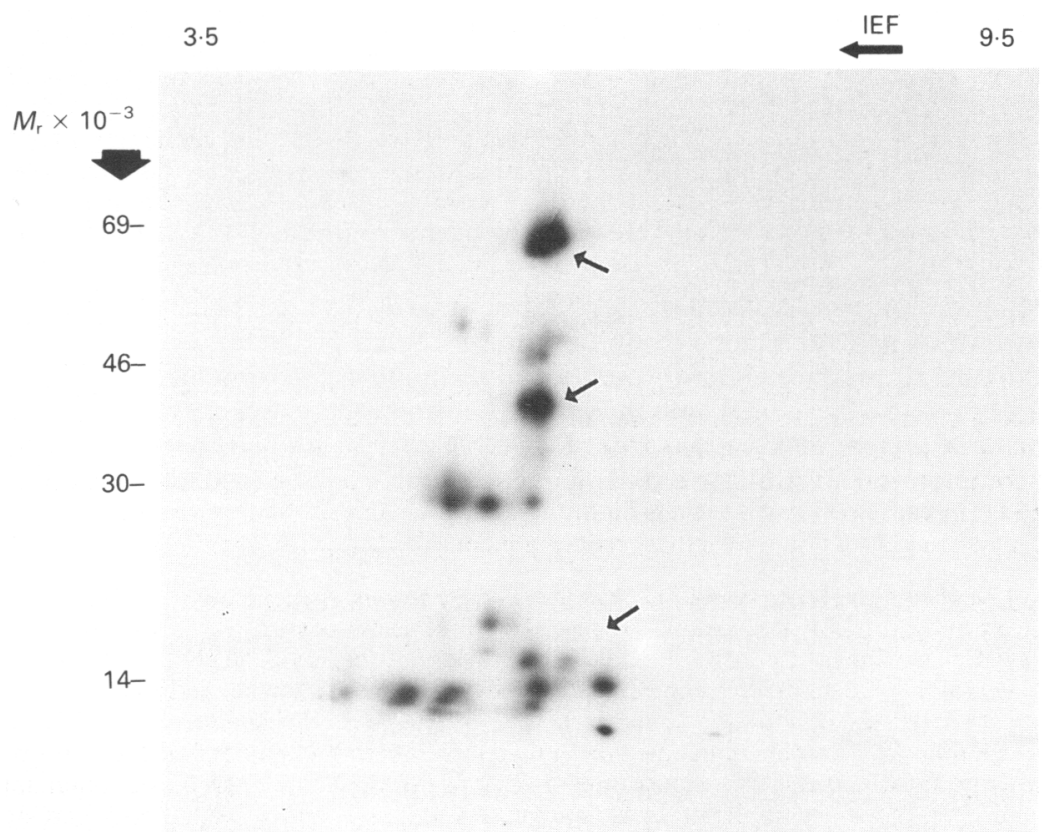

Fig. 1. Two-dimensional electrophoretic pattern of proteins secreted by Day-5 mouse blastocysts. Blastocysts were incubated in $\left[{ }^{35} \mathrm{~S}\right]$ methionine to produce embryo-conditioned medium containing labelled secreted proteins which were separated as described in Materials and Methods'. Approximately 10000 c.p.m. TCA-precipitable labelled protein were loaded onto the gel and fluorographic exposure was for 7 days. Protein 'spots' marked with arrows are secreted by Day- 5 blastocysts and outgrown blastocysts.

\section{Antiviral activity assay}

Figure 3 shows the assay plate comparing standard IFNs with control medium, embryoconditioned medium and embryo lysate collected after $48 \mathrm{~h}$ culture in Exp. 2 . The sensitivity of the assay (i.e. the concentration of standard IFN yielding a $50 \%$ plaque reduction) was 1.25 units of reference IFN- $\alpha$ and 1.0 units of reference IFN- $\beta$. No antiviral activity was found at any dilution in conditioned medium either from Day-5 blastocysts in Exp. 1 or from attached and spreading blastocysts in Exp. 2. Likewise, embryo lysates in both experiments showed no antiviral activity. 


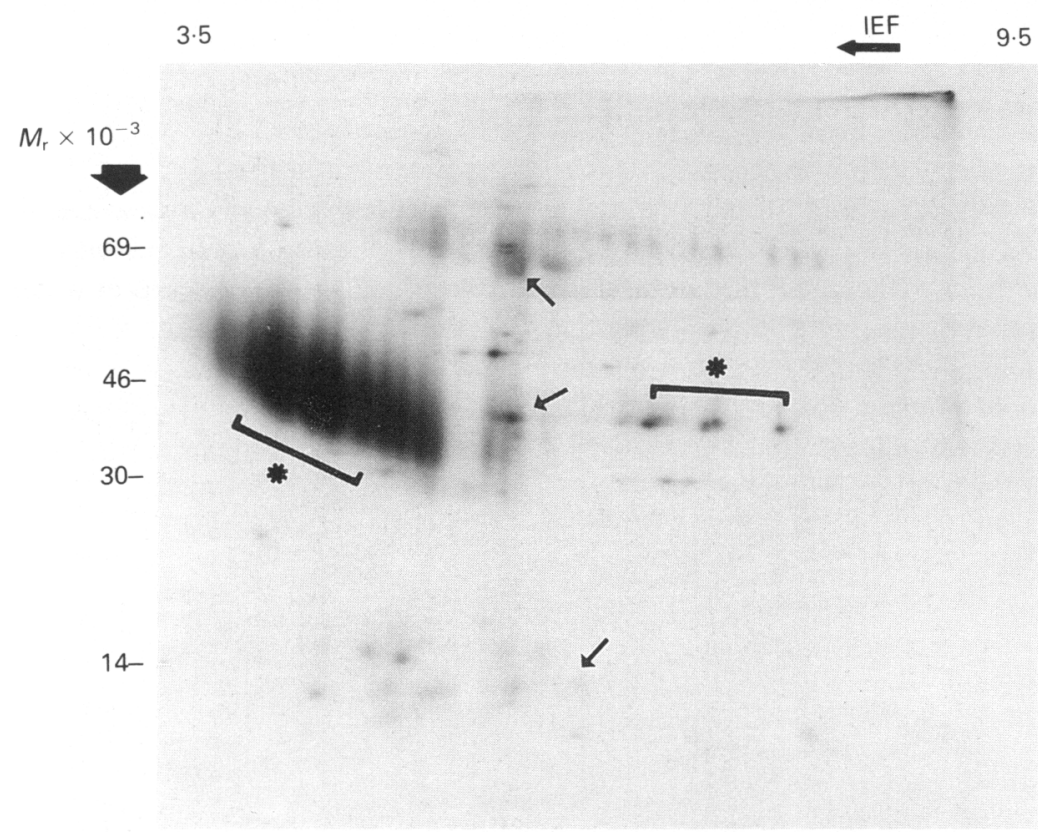

Fig. 2. Pattern of proteins secreted by trophoblast outgrowths after $24 \mathrm{~h}$ culture. Day- 5 mouse blastocysts which had been cultured on fibronectin-coated plates for $24 \mathrm{~h}$ were incubated in $\left[{ }^{35}\right.$ S]methionine to produce embryo-conditioned medium. Approximately 10000 c.p.m. TCA precipitable protein were loaded onto the gel and fluorographic exposure was for 7 days. Major new 'spots' not present in secretions from Day-5 blastocysts are marked with asterisks, while proteins common to Day-5 blastocysts and outgrown blastocysts, including small amounts of those of $M_{\mathrm{r}} 10000-20000$, are marked with arrows.

Since the highest concentration used in the assay was the undiluted sample, this means that the activity from mouse blastocyst, if present at all, is less than 0.02 units/embryo $/ 24 \mathrm{~h}$.

\section{Induction of decidualization}

In all animals, instillation of oil into the uterus resulted in the expected decidual reaction as noted in increased uterine weights after $72 \mathrm{~h}$ (Table 1). The decidual reaction extended the length of the entire uterine horn. Instillation of DPBS failed to induce a decidual reaction throughout the horn, although a small site was often observed at the site of injection, presumably due to local trauma. IFN- $\alpha$ at doses up to 2250 units failed to induce a decidual response beyond that found with DPBS.

\section{Discussion}

The sheep conceptus produces oTP-1 in substantial amounts beginning as early as Day 8 (Ashworth \& Bazer, 1989) with secretion increasing to over $100 \mu \mathrm{g} /$ conceptus (or greater than $1 \times 10^{6}$ units of antiviral activity/conceptus) per day as the embryo-maternal interface develops (Roberts, 1989). In the mouse, embryo-maternal interaction is established on Day 5 as the blastocyst attaches and invades the endometrium, and so, if IFN-like proteins do mediate maternal recognition of pregnancy in this species, they should be present within this time frame. The results of this study, however, provided no evidence that interferon-like proteins are produced by the peri-implantation mouse embryo, or that IFNs induce the maternal recognition response (i.e. decidualization). 
a

b

g h

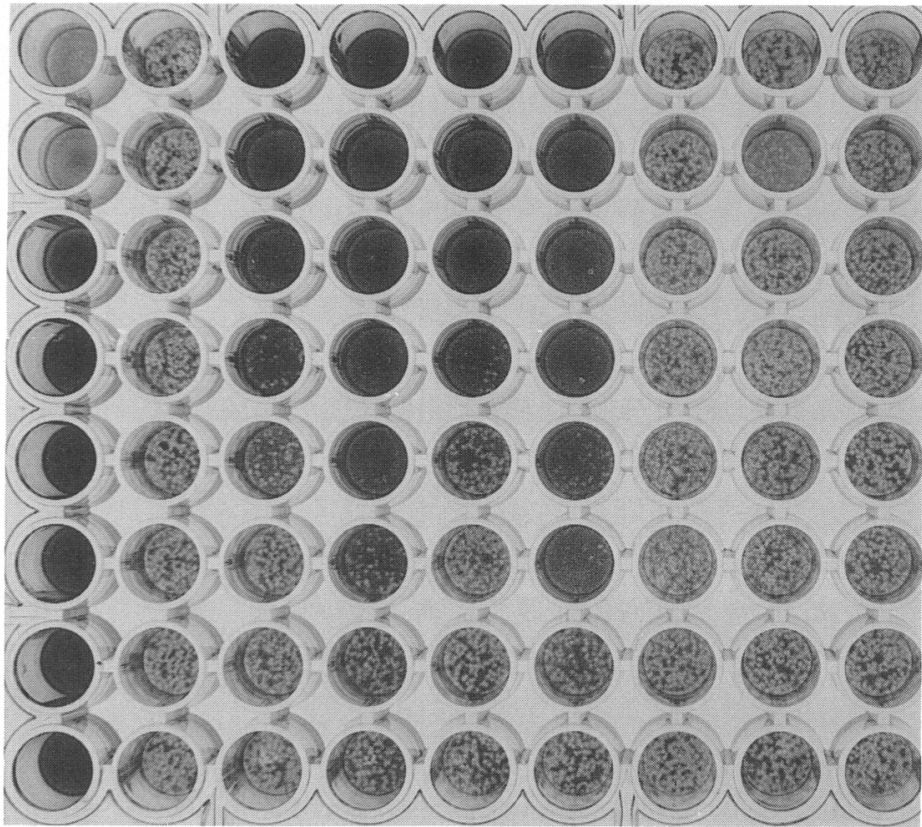

Fig. 3. Antiviral activity assay using vesicular stomatitis virus plaque formation in L929 cell monolayers. Monolayers of L929 cells were grown and challenged with virus as described in 'Materials and Methods'. (a) Unchallenged L929 cells. (b) Viral plaques in L929 cells. (c-h) Serial dilutions (1:3) of IFN standards and samples with highest concentration in the top row: (c and e) IFN- $\alpha$ standard starting at 110 units/well; ( $d$ and $f$ ) IFN- $\beta$ starting at 380 units/well; (g) Control medium starting with $50 \mu \mathrm{l} /$ well; (h) Lysate from 47 blastocysts after $48 \mathrm{~h}$ in outgrowth culture. (i) Conditioned medium from outgrowth culture between 24 and $48 \mathrm{~h}$ starting with $50 \mu \mathrm{l} /$ well.

Table 1. Effects of instillation of interferon- $\alpha$ on the mouse uterus

\begin{tabular}{lcc}
\hline Treatment* & $\begin{array}{c}\text { No. of } \\
\text { mice }\end{array}$ & $\begin{array}{c}\text { Wt of uterine horn } \\
(\mathrm{mg}) \dagger\end{array}$ \\
\hline None & 6 & $28 \cdot 3 \pm 1 \cdot 5$ \\
Oil & 17 & $183 \cdot 3 \pm 18 \cdot 7$ \\
DPBS & 4 & $48 \cdot 7 \pm 8 \cdot 6$ \\
IFN- $\alpha$ & & \\
$\quad 83$ units & 3 & $37 \cdot 6 \pm 2 \cdot 3$ \\
$\quad 250$ units & 3 & $39 \cdot 7 \pm 6 \cdot 2$ \\
750 units & 3 & $43 \cdot 0 \pm 1 \cdot 4$ \\
2250 units & 4 & $41 \cdot 8 \pm 2 \cdot 2$ \\
\hline
\end{tabular}

* Ovariectomized mice were primed with progesterone and oestradiol-17 $\beta$ as described in 'Materials and Methods'. Treatment substances were injected intraluminally in a volume of $10 \mu \mathrm{l}$.

†At $72 \mathrm{~h}$ after treatment; values are means \pm s.e.m. 
Antiviral activity was not found in either the early attachment-stage Day-5 blastocyst or after considerable trophoblast growth and differentiation in vitro. Neither the conditioned medium collected over a $24 \mathrm{~h}$ period nor the lysed embryos had any detectable activity. To compensate for the relatively small size of the mouse blastocyst at implantation, about 50 embryos were pooled and cultured in a minimal volume to produce a concentrated conditioned medium. Nevertheless, the sensitivity of the antiviral activity assay is limited, and it is possible that IFN-like proteins are made by the mouse blastocyst, but in quantities too small to detect (i.e. $<\sim 0.02$ units/embryo/24 h). If this is the case though, it seems unlikely that these proteins would interact with the endometrium in the same manner as in the sheep and cow in which such large quantities of trophoblast protein are secreted.

The lack of IFN activity in embryo secretions is consistent with our observation that exogenous IF $N-\alpha$ is ineffective in inducing the decidual reaction in the mouse. The decidualization criterion used was an increase in uterine weight. Earlier events in the decidual reaction include an increased vascular permeability and changes in RNA synthesis, nucleolar ultrastructure and endometrial protein secretion (see Nieder, 1989). Some of the responses occur, without subsequent decidua formation, in the oestrogen-sensitized uterus in response to saline instillation alone and in the non-sensitized uterus after oil instillation. The dissociation of these early responses from gross decidualization suggests a multi-factorial mechanism of decidual induction, part of which could involve IFN-like proteins. The ability of IFN- $\alpha$ to evoke these early responses was not tested, but it is clear that the full decidual reaction does not result from this treatment.

The results therefore imply that IFN-like proteins such as OTP-1 and bTP-1 are not a universal mechanism for the maternal recognition of pregnancy. This may not be surprising since the method of implantation and the developmental stage of the blastocyst at the time of implantation vary markedly between animals of different types. The sheep blastocyst implants superficially after attaining a filamentous form with complete attachment taking several weeks. The mouse blastocyst, on the other hand, is invasive with attachment and implantation underway by the end of Day-5. Also, in the ungulates the maternal recognition of pregnancy appears to involve inhibition of luteolytic prostaglandin release by the uterus. Rodents have a totally different mode of luteal rescue and implantation is associated with increased endometrial prostaglandin synthesis. Hence, rodents may not have developed this interferon-mediated mechanism for recognition of pregnancy. Although IFN activity does not appear to have a role in implantation in the mouse, several different proteins are produced in a stage-specific fashion during this time and remain, along with other diffusible molecules such as platelet-activating factor (Spinks \& O'Neill, 1988), candidates for the mediator of maternal recognition of pregnancy.

This study was supported by grant HD 25236 from the National Institute of Child Health and Human Development. We thank Dr Nancy Bigley and Scott Tenenbaum for assistance with the antiviral activity assay.

\section{References}

Armant, D.R., Kaplan, H.A. \& Lennarz, W.J. (1986) Fibronectin and laminin promote in vitro attachment and outgrowth of mouse blastocysts. Devl Biol. 116, 519-523.

Ashworth, C.J. \& Bazer, F.W. (1989) Changes in ovine conceptus and endometrial function following asynchronous embryo transfer or administration of progesterone. Biol. Reprod. 40, 425-433.

Brinster, R.L. (1971) In vitro culture of the embryo. In Pathways to Conception; the Role of the Cervix and Oviduct in Reproducion, pp. 245-277. Ed. A. I. Sherman. Charles C. Thomas, Springfield.

Campbell, J.B., Grunberger, T., Kochman, M.A. \&
White, S.L. (1975) A microplaque reduction assay for human and mouse interferon. Can. J. Microbiol. 21, 1247-1253.

Finn, C.A. \& Martin, L. (1972) Endocrine control of the timing of endometrial sensitivity to a decidual stimulus. Biol. Reprod. 7, 82-86.

Fowler, R.E. \& Edwards, R.G. (1957) Induction of superovulation and pregnancy in mature mice by gonadotropins. J. Endocr. 15, 374-384.

Nieder, G.L. (1989) Analysis of proteins secreted by mouse embryos developing in vivo and in vitro. $J$. exp. Zool. 252, 134-142.

Nieder, G.L. \& Baker, D.J. (1989) Protein secretion by 
peri-attachment mouse blastocysts, inner cell masses and trophoblast vesicles. Biol. Reprod. 40 (Suppl. 1), 122 , abstr.

Nieder, G.L. \& Macon, G.R. (1987) Oviducal and uterine protein secretion during early pregnancy in the mouse. J. Reprod. Fert. 81, 287-294.

Nieder, G.L., Weitlauf, H.M. \& Suda-Hartman, M. (1987) Synthesis and secretion of stage-specific proteins by peri-implantation mouse embryos. Biol. Reprod. 36, 687-699.

Roberts, R.M. (1989) Conceptus interferons and materna] recognition of pregnancy. Biol. Reprod. 40, 449-452.
Schellekens, H. \& van der Meide, P.H. (1987) Production of animal interferons. In The Interferon System, $a$ Current Review to 1987, pp. 113-120. Eds S. Baron, F. Dianzani, G. J. Stanton \& W. F. Fleischmann. University of Texas Press, Austin.

Spinks, N.R. \& O'Neill, C. (1988) Antagonists of embryoderived platelet activating factor prevent implantation in the mouse. J. Reprod. Fert. 84, 89-98.

Weitlauf, H.M. \& Suda-Hartman, M. (1988) Changes in secreted uterine proteins associated with embryo implantation in the mouse. J. Reprod. Fert. 84, $539-549$.

Received 23 May 1989 